\title{
CHESSWARE RECEIVED
}

\section{CHESS ENDGAMES VOL. 3}

\author{
Ken Thompson
}

AT\&T Bell Laboratories

The Editors are pleased to acknowledge receipt of a follow-up to the first and second CD-ROMs with chess endgames (see ICCA Journal, Vol. 14, No. 1, p. 22 and Vol. 15, No. 3, p. 149).

Volume 3 contains the following 5-piece endgames (in Ken Thompson's notation): NNvB, NNvN, NNvP, NNvQ, NNvR, PRvB, QvPR, QvQR, QvRB, QvRN, QvRR, QRvB, RvBB, RvBN, RvNN, RvPB, RvPN, RvQB, RvQN, RvRB, RvRN, RBvB, RNvB, RRvB, with artwork by Lillian Schwartz and Gerard Holzmann.

For some of the most important results, the reader is referred to the Editors' Note on pp. 86-90 of this issue.

The price of this CD is US $\$ 10 .--$, cash or by cheque made payable to AT\&T Bell Laboratories, sent to:

Ken Thompson

AT\&T Bell Laboratories, Room 2C579

600 Mountain Avenue, Murray Hill

New Jersey 07974/USA

Email: ken@research.att.com

\section{INFORMATION FOR CONTRIBUTORS}

\section{Submission of material}

Contributions to the Journal are welcomed in any form, although preferably by E-mail or on an MS-DOS formatted 5.25 or 3.5 inch floppy disk. In case contributors prepare their manuscripts with wordprocessors, it should be noticed that text files in WordPerfect, Tex or Troff format can be processed directly by the Editors, thereby alleviating their task considerably.

\section{Abstracting and indexing}

Contributors may be interested to know that the ICCA Journal, as of Vol. 10, No. 1, is a source for the Institute for Scientific Information ${ }^{\otimes}$ (ISI) for inclusion in the CompuMath Citation Index ${ }^{\circledast}\left(\mathrm{CMCI}^{\circledast}\right)$, the Automatic Subject Citation Alert (ASCA ${ }^{\circledR}$ ) and SCISEARCH ${ }^{\otimes}$, ISI's on-line database. Author abstracts are now also available in Current Contents on Diskette ${ }^{\circledR}$, and in on-line files such as SCISEARCH ${ }^{\circledast}$ and Current Contents Search ${ }^{\circledast}$. Moreover, the Journal is also a source for the Information Company R.R. Bowker for inclusion in the International Serials Database which is a source for Ulrich's International Periodicals Directory and the DIALOG on-line service.

Being included in the $\mathrm{CMCI}^{\oplus}$, the ICCA Journal is one of the 400 Journals in mathematics, computer science, statistics, operations research, and related disciplines which is abstracted and/or indexed and/or available as tearsheets; this means that the Journal now is accessible in (on-line) database form. 